\title{
Bağlama Öncesi Su Yüzeyi Profilinin Deneysel ve Sayısal Analizi
}

\author{
Oğuzhan Esatoğlu ${ }^{1 *}$, Birol Kaya ${ }^{2}$

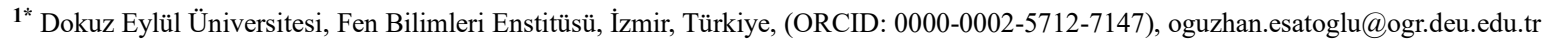 \\ 2 Dokuz Eylül Üniversitesi, Mühendislik Fakültesi, İnşaat Mühendisliği Bölümü, İzmir, Türkiye (ORCID: 0000-0002-7655-526X), birol.kaya@deu.edu.tr
}

(International Conference on Design, Research and Development- 15 - 18 Aralık 2021)

(DOI: 10.31590/ejosat.1039504)

ATIF/REFERENCE: Esatoğlu, O. \& Kaya, B. (2021). Bağlama Öncesi Su Yüzeyi Profilinin Deneysel ve Sayısal Analizi. Avrupa Bilim ve Teknoloji Dergisi, (32), 282-287.

$\ddot{O} \mathbf{z}$

Bu çalışmada, bağlama arkasında oluşan su yüzeyi profilinin deneysel ve sayısal olarak analizi gerçekleştirilmiştir. Deneyler, Dokuz Eylül Üniversitesi Hidrolik Laboratuvarı'nda bulunan ve eğimi değiştirilebilen açık kanal deney düzeneğinin mansap kısmına eşik konularak gerçekleştirilmiştir. Yapılan deneylere ait başlangıç koşulları kullanılarak tedrici değişken akımlar için su yüzeyinin diferansiyel denklemi Euler Yöntemi, Dördüncü Mertebeden Runge Kutta Yöntemi, Standart Adım Yöntemi, Doğrudan Adım Yöntemi ve Diferansiyel Kuadratur Yöntemi ile sayısal olarak çözülmüştür. Deneysel veriler kullanılarak farklı sayısal yöntemlerden elde edilen göreceli hatalar birbirleriyle karşılaştırılmış ve yöntemlerin doğrulukları irdelenmiştir.

Anahtar Kelimeler: Tedrici Değişken Akım, Sayısal Analiz, Fiziksel Model.

\section{Numerical and Experimental Analysis of Water Surface Profile Back of The Regulator}

\begin{abstract}
In this study, experimental and numerical analysis of the water surface profile formed back of the regulator was carried out. The experiments were performed by placing a threshold on the downstream part of the open channel experimental setup, which is located in Dokuz Eylul University Hydraulics Laboratory and whose slope can be changed. Using the initial conditions of the experiments, the differential equation of the water surface for the gradually varied flows was solved numerically by the Euler Method, the Fourth Order Runge Kutta Method, the Standart Step Method, the Direct Step Method and the Differential Quadrature Method. By using experimental data, the relative errors obtained from different numerical methods were compared with each other and the accuracy of the methods was examined.
\end{abstract}

Keywords: Gradually Varied Flow, Numerical Analysis, Physical Model.

\footnotetext{
*Sorumlu Yazar: oguzhan.esatoglu@ogr.deu.edu.tr
} 


\section{Giriş}

Günümüzde, artan iklim sorunları ve yağışların düzensizliği istenilen zaman ve miktarda suya olan ulaşımı zorlaştırmaktadır. $\mathrm{Bu}$ durum, suya ulaşımı daha kolay hale getirebilmek amacıyla baraj, bağlama gibi su biriktirme tesislerin inşasını gerekli kılmaktadır. $\mathrm{Bu}$ tesislerin planlanması, projelendirilmesi ve yapımı, hidrolik mühendisliğinin ilgi alanları içerisindedir. Özellikle, projelendirme aşamasında yapının güvenilir ve ekonomik olması tüm mühendislik alanlarında olduğu gibi hidrolik mühendisliğinde de önemli bir yer teşkil etmektedir. Özellikle, bağlama gibi su kabartıcı yapıların arkasında oluşacak profilin uzunluğunu belirlemek tasarım aşamasında, özellikle bağlamanın yer seçimi açısından büyük önem arz etmektedir.

Bağlama arkasında oluşacak profile ait temel denklem, doğrusal olmayan adi diferansiyel denklem türünde olup, tedrici değişken akım için su yüzeyinin diferansiyel denklemi olarak adlandırılmaktadır. Bu denklemin çözümü için sayısal olarak birçok yöntem kullanılmaktadır (Chow, 1959). Sayısal çözüm için bu çalışmada kullanılacak yöntemlere ilişkin literatürde mevcut bulunan çalışmalar aşağıda şekilde sunulabilir.

Zaghloul ve Darwish (1987), tedrici değişken akımlar için su yüzeyinin diferansiyel denklemini doğrudan adım yöntemiyle çözen Lotus 1-2-3 tabanlı bir bilgisayar programı geliştirmiştir.

Paine (1992), tedrici değişken akımlar için su yüzeyinin diferansiyel denkleminin çözümünde en kabul gören yöntemin Standart Adım Yöntemi olduğunu belirtmiştir. Standart Adım Yöntemi' nde çok fazla girdi olması sebebiyle yöntemin çözüm hızını etkileyen bu durumu çözmek için yeni bir algoritma geliştirmiştir.

Demirel ve Tozluk (2002), tedrici değişken akımlar için su yüzeyi denkleminin çözümünde kullanılan Euler Yöntemi’ nde hesap için gerekli adım sayısını araştırmıştır. Çalışmada, önceden belirlenen hata miktarını aşmayacak hesap adım sayısının belirlenmesi amaçlanmıştır.

Öztürkmen (2008), sabit debi koşullarında, sabit taban eğimine sahip kanalda 12 farklı tipte taban eşiği kullanarak açık kanalın memba ve mansabında meydana gelen su yüzeyi değişimlerini incelemiştir.

Basha (2009), küçük eğimli kanallarda, kanalın mansabında bağlama ve serbest düşü olması durumları için deneysel çalışmalar gerçekleştirmiştir. Yapılan deneysel durumlara ait sayısal çözümleri Chen ve Wang (1969) tarafından geliştirilen boyutsuz yöntem ile Standart Adım yöntemleriyle gerçekleştirmiştir.

Kaya (2010), tedrici değişken akımlar için su yüzeyinin diferansiyel denklemini Diferansiyel Kuadratur Yöntemi' ni kullanarak çözmüş ve bu yöntem ile elde ettiği sonuçları Doğrudan Adım Yöntemi ile yapılan çözümlerle karşılaştırmıştır. Araştırmacı Diferansiyel Kuadratur Yöntemi' nin diğer yönteme kıyasla az sayıda hesap noktası kullanarak makul ölçüde sonuçlar verdiğini belirtmiştir.

Marcacuzco ve Vargas (2019), prizmatik kanallarda tedrici değişken akımlar için su yüzeyinin diferansiyel denklemini dördüncü mertebeden Runge Kutta Yöntemi ile çözen bir Matlab program kodu geliştirmiştir.
Görüldüğü üzere, tedrici değişken akımlar için su yüzeyinin diferansiyel denklemi farklı yöntemlerle çözülürken daha çok belirli bir yöntem ile sayısal çözüm yapılmaktadır. Literatürde, sayısal yöntemlerle elde edilen sonuçların deneysel verilerle kıyaslanarak, gerçek durumdan ne kadar farklı sonuçlar verdiği ile ilgili çalışmalar sayıca yetersizdir. $\mathrm{Bu}$ anlamda, yapılan çalışma literatürdeki mevcut boşluğu, sayısal yöntemlerle elde edilen sonuçları, deneysel verilerle birlikte değerlendirmesi bakımından doldurmaktadır.

\section{Materyal ve Metot}

\subsection{Deneysel Çalışma}

Deneysel çalışmalar, Şekil 1' de gösterilen Dokuz Eylül Üniversitesi Hidrolik Laboratuvarı' nda mevcut bulunan $25 \mathrm{~cm}$ genişliğe ve 9,2 m uzunluğa sahip açık kanal düzeneğinde gerçekleştirilmiştir.

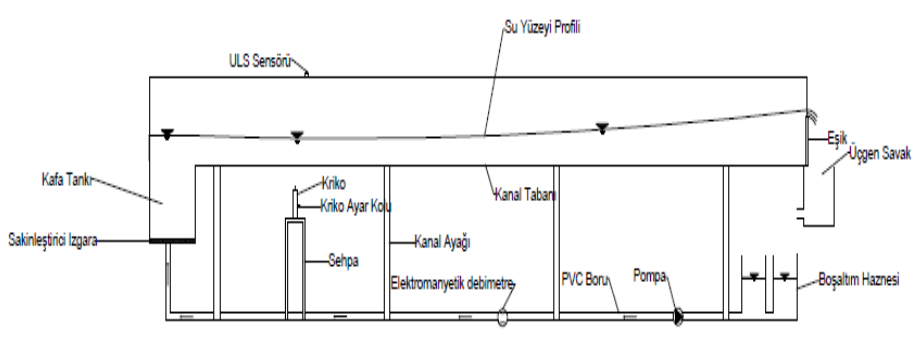

Şekil 1. Deney Düzeneğinin Şematik Görünümü

Şekil 1' de görülen açık kanal deney düzeneği 9,2 m genişliğe, $25 \mathrm{~cm}$ genişliğe ve dikdörtgen enkesite sahiptir. Düzenek, her biri 500 litre su hacmine sahip iki adet hazneden beslenmekte olup, hazneden kanala su girişi 2 inç çapa sahip PVC malzemeden yapılmış boru ve $1 \mathrm{~kW}$ güce sahip pompa ile gerçekleşmektedir. Kanala giriş yapan suyun debisi, pompa üzerinde bulunan kelebek vana vasitasıyla ayarlanmaktadır. Belirli bir vana açıklığına karşılık gelen debi boru üzerine yerleştirilmiş elektromanyetik debimetreyle hassas bir şekilde belirlenmektedir. Ayrıca, kanala giriş yapan suyun türbülans etkisi kafa tankının tabanında bulunan sakinleştirici ızgaralar ile azaltılmaktadir.

Düzeneğin memba kısmında eğim değişikliği yapabilmek amacıyla metal sehpa üzerine yerleştirilmiş bir kriko bulunmaktadır. Bu kriko, ayar kolu ile istenilen miktarda yükseltilerek kanalın memba ve mansap kısımları arasında kot farkı oluşturulmakta ve böylelikle düzenekte farklı taban eğimleri ile deney yapmak mümkün olmaktadır. Kriko yardımıyla kanalda oluşturulan eğim, laboratuvarda mevcut bulunan nivelman ile taban kotları ölçülerek belirlenmiştir.

Kanalın mansabında bağlama öncesi oluşan su yüzeyi profilini gözlemlemek amacıyla yüksekliği ayarlanabilir pleksiglas malzemeden imal edilmiş bir eşik bulunmaktadır. Çalışmalarda, bağlama öncesinde oluşan profillin tamamı gözlemlenmeye çalışılsa da hem pompanın debi kapasitesinin hem de kanal uzunluğunun yetersizliği sebebiyle profilin belirli bir parçası gözlemlenebilmiştir. Oluşturulan su yüzeyi profilinin, belirli noktalardaki derinlik ölçümleri ULS (Ultrasonik Level Sensor) cihazı ile belirlenmiştir. Bu cihazla ölçüm yapılırken, öncelikle derinlik ölçümü yapılacak kanal kesitlerinde taban 
okuması yapılmış, sonrasında akım kararlı akım durumu için bu kesitlerde mevcut su yüzeyinde bir ölçüm daha gerçekleştirilerek su derinlikleri elde edilmiştir.

\subsection{Sayısal Çözüm}

\subsubsection{Temel Denklem}

Prizmatik bir kanalda oluşan tedrici değişken akım için su yüzeyi profilini açıklayan denklem, birinci mertebeden doğrusal olmayan diferansiyel bir denklem olup, (1) denklemi ile ifade edilmektedir (Moglen, 2015).

$$
\frac{d y}{d x}=\frac{S_{0}-S_{f}}{1-F r^{2}}
$$

$\mathrm{Bu}$ denklemde bulunan $S_{0}$ kanal taban eğimine, $S_{f}$ (2) denklemi ile ifade edilen enerji çizgisi eğimine, $\mathrm{Fr}$ ise boyutsuz bir parametre olup, (3) denklemi ile ifade edilen Froude sayısına karşılık gelmektedir. Enerji çizgisinin eğimini ifade edebilmek amacıyla bu çalışmada Manning Denklemi kullanılmıştır (Manning, 1891).

$$
\begin{gathered}
S_{f}=\frac{Q^{2} n^{2}}{A^{2} R^{\frac{4}{3}}} \\
F r=\frac{Q^{2} B}{g A^{3}}
\end{gathered}
$$

(2) ve (3) denklemlerinde mevcut bulunan $Q$ hacimsel debiye, $n$ kanal cidar türüne bağlı olarak değişen Manning pürüzlülük katsayısına, $A$ ıslak kesit alanına, $R$ hidrolik yarıçapa, $B$ su yüzeyi genişliğine, $g$ ise yerçekimi ivmesine karşılık gelmektedir.

\subsection{Sayısal Çözüm Yöntemleri}

\subsubsection{Euler Yöntemi}

Euler Yöntemi, sayısal analizde doğrusal olmayan diferansiyel denklemlerin çözümü için sıklıkla kullanılmaktadır. Tedrici değişken akımlar için su yüzeyi profilinin diferansiyel denklemi de bu gruba girdiğinden, mevcut çalışmada sayısal çözüm yöntemi olarak kullanılmıştır.

Gerçekleştirilen deneysel çalışmada, eşik arkasında ölçülen su derinliği başlangıç koşulu olarak kullanılarak bir sonraki kesitteki su derinliği Euler Yöntemi ile (4) denklemindeki gibi belirlenebilmektedir (Esfandiari, 2017).

$$
y_{i+1}=y_{i}+\Delta x y_{i}^{\prime}
$$

(4) denkleminde bulunan $y_{i}$ deneysel çalışmadan elde edilmiş veya daha önceki çözüm adımında hesaplanmış derinlik değerine, $\Delta x, i+1$ kesitinin $i$ kesitine olan yatay mesafesine, $y_{i}^{\prime}$ ise (5) denklemi ile ifade edilen $i$ kesitindeki su yüzeyinin eğimine karşıllı gelmektedir.

$$
y_{i}^{\prime}=\left.\frac{d y}{d x}\right|_{i}=f\left(x_{i}, y_{i}\right)
$$

\subsubsection{Dördüncü Mertebeden Runge Kutta Yöntemi}

Dördüncü mertebeden Runge Kutta Yöntemi, tedrici değişken akımlar için su yüzeyinin diferansiyel denklemini sayısal olarak çözerken Euler Yöntemi' nin aksine (6) denkleminde görüldüğü üzere hesap yapılan iki kesit arasında temsili su yüzeyi eğiminin belirlenmesinde dört adet su yüzey, eğiminin ağırlıklı ortalamasını kullanmaktadır (Qian vd., 2011).

$$
y_{i+1}=y_{i}+\frac{1}{6}\left(k_{1}+2 k_{2}+2 k_{3}+k_{4}\right) \Delta x
$$

(6) denkleminde bulunan katsayılar (7)-(10) bağıntlarıyla elde edilebilmektedir.

$$
\begin{aligned}
& k_{1}=f\left(x_{i}, y_{i}\right) \\
& k_{2}=f\left(x_{i}+\frac{1}{2} \Delta x, y_{i}+\frac{1}{2} k_{1} \Delta x\right) \\
& k_{3}=f\left(x_{i}+\frac{1}{2} \Delta x, y_{i}+\frac{1}{2} k_{2} \Delta x\right) \\
& k_{4}=f\left(x_{i}+\Delta x, y_{i}+k_{3} \Delta x\right)
\end{aligned}
$$

\subsubsection{Doğrudan Adım Yöntemi}

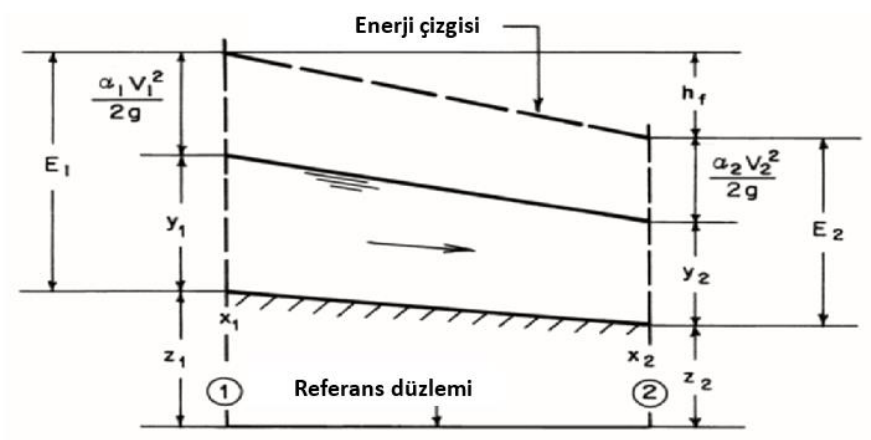

Şekil 2. Doğrudan Adım Yöntemi için Kanal Parçası

Doğrudan Adım Yöntemi, prizmatik kanallarda su yüzeyi profillerinin hesabında kullanılan klasik yöntemlerden birisidir. $\mathrm{Bu}$ yöntemle hesap yapılırken, Şekil 2' de gösterilen iki kesit arasında enerji denklemi yazılarak belirli bir derinliğin akış özellikleri bilinen kesitten ne kadar uzakta oluşacağı (11) denklemi ile belirlenebilmekedir (Chaudry, 2008).

$$
x_{2}=x_{1}+\frac{E_{2}-E_{1}}{S_{0}-\frac{1}{2}\left(S_{f 1}+S_{f 2}\right)}
$$

(11) denkleminde bulunan $E_{1}$ ve $E_{2}$ Şekil 2' den de görüldüğü üzere derinlik ve hız yüksekliği değerlerinin toplamından oluşan özgül enerji değerlerine, $x_{1}$ ve $x_{2}$ ise sirasıyla 1 ve 2 kesitlerinin konumuna karşılık gelmektedir.

Çalışmada kullanılan yöntemlerle elde edilen sayısal sonuçların birbirleriyle uygun bir şekilde karşılaştırılabilmesi gerekmektedir. Bu amaçla, sözü geçen sayısal yöntemde derinlik ölçümlerinin gerçekleştirildiği kesitlerdeki derinlik değerlerinin hesabının yapılması gerekmektedir. Fakat, görüldüğü üzere, bu yöntem ile belirli bir derinliğin bilinen kesitten ne kadar uzaklıkta oluşacağı bulunabilmektedir. Mevcut çalışmada, yöntem ile çözüm yapılırken, daha önceden belirlenen kesitlerde derinlik değerleri bulunacak şekilde bir iterasyon gerçekleştirilmiştir

\subsubsection{Standart Adım Yöntemi}

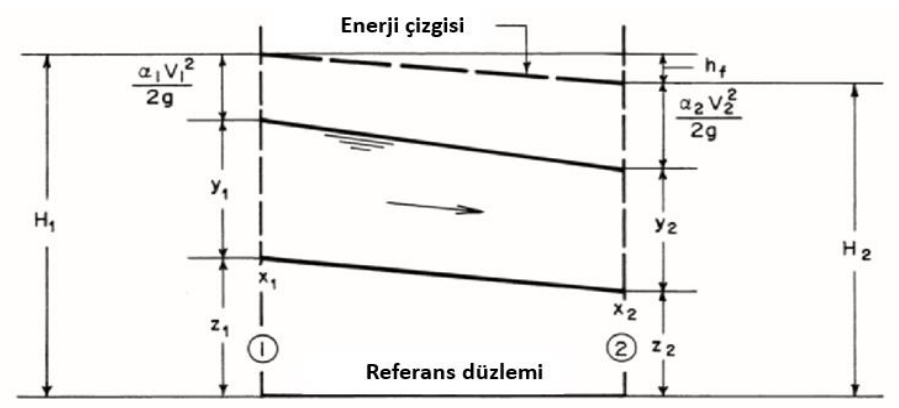

Şekil 3. Standart Adım Yöntemi için Kanal Parçası

Standart Adım Yöntemi, hem prizmatik hem de prizmatik olmayan kanallarda su yüzeyi profilinin belirlenmesinde 
kullanılan klasik yöntemlerden biridir. Yaygın olarak kullanılan HEC-RAS programı da bu yöntem temelinde çözümler yapmaktadır.

Şekil 3' de görüldüğü üzere Standart Adım Yöntemi ile hesap yapılırken iki kesit arasında yazılan (12) ile ifade edilen enerji denkleminden yararlanılmaktadır (Henderson, 1966).

$$
\frac{V_{1}^{2}}{2 g}+y_{1}+z_{1}=\frac{V_{2}^{2}}{2 g}+y_{2}+z_{2}+\frac{\Delta x}{2}\left(S_{f 1}+S_{f 2}\right)
$$

(12) denkleminde bulunan $\frac{V_{1}^{2}}{2 g}$ ve $\frac{V_{2}^{2}}{2 g}$ sirasiyla 1 ve 2 kesitlerindeki hız yüksekliklerine, $z_{1}$ ve $z_{2}$ ise 1 ve 2 kesitlerdeki kanal tabanının referans düzlemine olan düşey uzaklığını ifade etmektedir. Bu denklemde 2 kesitindeki su derinliği $y_{2}$ dişında tüm parametreler bilindiğinden, herhangi bir sayısal yöntemle kök değerinin bulunması gerekmektedir. Çalışmada, bu amaçla Newton-Raphson Yöntemi kullanılmıştır. (Chaudry, 2008).

\subsubsection{Diferansiyel Kuadratur Yöntemi}

Fizik ve Matematikte diferansiyel denklemlerin çözümü için yaygın olarak kullanılan yöntem ilk olarak Kaya (2010) tarafından tedrici değişken akımlar için su yüzeyi profilinin diferansiyel denklemi üzerine uygulanmıştır. (1) denklemi ile ifade edilen tedrici değişken akımlar için su yüzeyi profilinin denklemi Diferansiyel Kuadratur Yöntemi' nde (13) denklemi ile ifade edilebilir (Kaya, 2010).

$$
\sum_{j=1}^{N} a_{i j} x_{j}=\left.\frac{1-\frac{Q^{2} B}{g A^{3}}}{S_{0}-\left[\frac{n Q U^{2 / 3}}{A^{5 / 3}}\right]^{2}}\right|_{i}
$$

(13) denkleminde bulunan $U$ islak kesit çevresine, denklemin sol tarafinda bulunan $a_{i j}$ ise diferansiyel kuadratur yöntemine özgü ağırlıklıklaştırılmış katsayıyı ifade etmekte olup, $\mathrm{Bu}$ çalışmada Quan ve Chang (1989a) tarafindan geliştirilen ve (14)(15) denklemleriyle ifade edilen yaklaşım kullanılmıştır.

$$
\begin{aligned}
& a_{i j}=\frac{1}{y_{j}-y_{k}} \prod_{k=1, k \neq i, j}^{N} \frac{y_{i}-y_{k}}{y_{j}-y_{k}}, \quad j \neq i \\
& a_{i i}=\sum_{k=1, k \neq i}^{N} \frac{1}{y_{i}-y_{k}}
\end{aligned}
$$

(13) denkleminin sağ tarafinın hesabı için, $y_{i}$ değerlerinin seçimi büyük önem taşımaktadır. $\mathrm{Bu}$ amaçla, derinliklerin seçiminde (16) denklemiyle ifade edilen Chebyshev ağ yapısı kullanılmıştır (Shu, 2000).

$$
y_{i}=a-(d-a) \frac{\left(\cos \left[\frac{(2 i-1) \pi}{2 N}\right]-\cos \left(\frac{\pi}{2 N}\right)\right)}{2 \cos \left(\frac{\pi}{2 N}\right)}
$$

(16) denkleminde mevcut bulunan $i$ hesap yapilan kesit numarasina, $N$ ise toplam hesap noktası sayısina, $a$ ve $d$ ise sırasıyla hesap yapılan aralığın alt ve üst derinlik değerlerine karşılık gelmektedir. Bu çalışmada oluşturulan su yüzeyi profilli için alt sınır değeri kanalda oluşan üniform su derinliğine, üst değer ise eşik arkasında ölçülen su derinliğine karşılık gelmektedir.

Bu yöntemde, derinliklerin seçilmesi ve ağırlık katsayılarının hesaplanmasının ardından (13) denklemi $N-1$ değişkenden oluşan $N-1$ adet denklem takımına karşılık gelmektedir. Sözü geçen denklem takımı çalışmada, ters matris yöntemi ile çözülmüş olup, seçilen derinliklere karşılık gelen konumlar hesaplanmıştır. Bulunan konumlar, deneysel ölçüm noktalarına doğrudan karşılık gelmediğinden, bu kesitler için doğrusal enterpolasyon gerçekleştirilmiştir.

\section{Araştırma Sonuçları ve Tartışma}

Deneysel çalışmalar sabit eğim, sabit eşik yüksekliği ve üç

\begin{tabular}{|c|c|c|c|}
\hline Deney No & Debi $(\mathrm{L} / \mathrm{s})$ & $\begin{array}{c}\text { Eşik } \\
\text { Yüksekliği } \\
\text { (cm) }\end{array}$ & $\begin{array}{l}\text { Kanal } \\
\text { Taban } \\
\text { Eğimi }\end{array}$ \\
\hline 1 & 3 & \multirow{3}{*}{1,5} & \multirow{3}{*}{0,002} \\
\hline 2 & 2,4 & & \\
\hline 3 & 1,2 & & \\
\hline
\end{tabular}
farklı debi durumda gerçekleştirilmiştir. Tablo 1' de deneysel çalışmalardaki mevcut değişkenlerin değerleri yer almaktadır.

Tablo 1. Yapılan Deneysel Çalışmalara Ait Değişkenlerin Değerleri

Çalışmada, sayısal çözümler Matlab paket programında yazılmış kodlar aracılığıyla yapılmış olup, kanal kesiti pleksiglas malzemeden oluştuğundan Manning pürüzlülük katsayısı $n=$ 0,011 olarak alınmıştır. Elde edilen sonuçlar ve karşılaştırmalar Şekil 4-6' da görülmektedir.

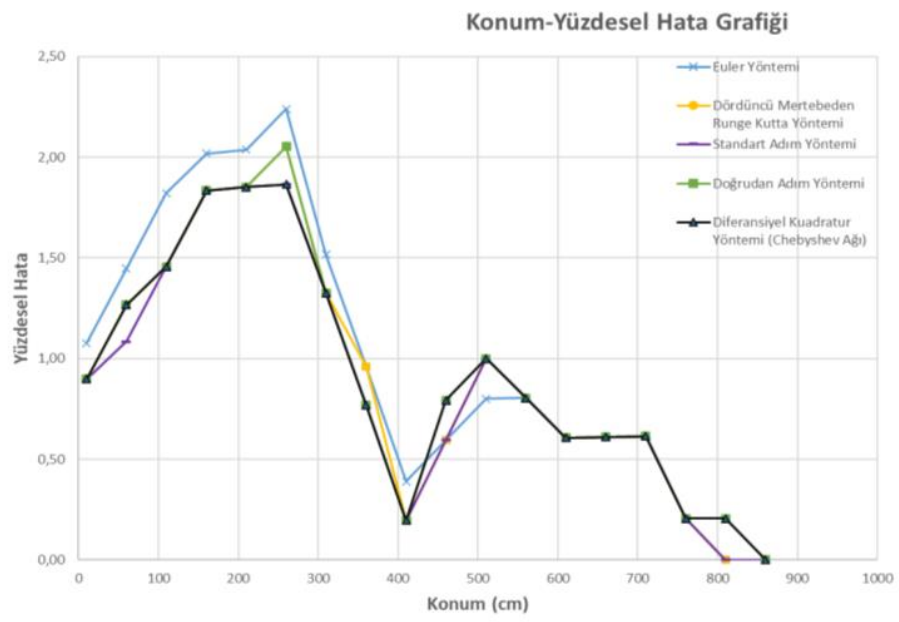

Şekil 4. 1 numaralı deney durumu için saylsal yöntemlerdeki yüzdesel rölatif hataların konuma bă̆lı değişimi

Çalışmada, sayısal yöntemlerden hangisinin daha iyi sonuç verdiğini belirleyebilmek amaciyla maksimum yüzdesel rölatif hata ve karesel ortalama hata $(\mathrm{KOH})$ kullanılmıştır. Yapılan deneysel durumlar için kullanılan sayısal yöntemlerden elde edilen hatalar Tablo 2-4' de sunulmuştur. 
Tablo 2. 1 numaralı deney durumu için kullanılan sayısal yöntemlerden elde edilen hata değerleri

\begin{tabular}{l|c|c}
\hline Sayısal Yöntem & $\begin{array}{c}\text { Maksimum } \\
\text { Yüzdesel } \\
\text { Rölatif } \\
\text { Hata }\end{array}$ & $\begin{array}{c}\text { Karesel } \\
\text { Ortalama } \\
\text { Hata }\end{array}$ \\
\hline Euler Yöntemi & 2,24 & 0,066 \\
\hline $\begin{array}{l}\text { Dördüncü Mertebeden } \\
\text { Runge Kutta Yöntemi }\end{array}$ & 2,05 & 0,060 \\
\hline Standart Adım Yöntemi & 1,87 & 0,058 \\
\hline $\begin{array}{l}\text { Doğrudan Adım Yöntemi } \\
\text { Diferansiyel Kuadratur }\end{array}$ & 2,05 & 0,060 \\
\hline Yöntemi & 1,87 & 0,058 \\
\hline
\end{tabular}

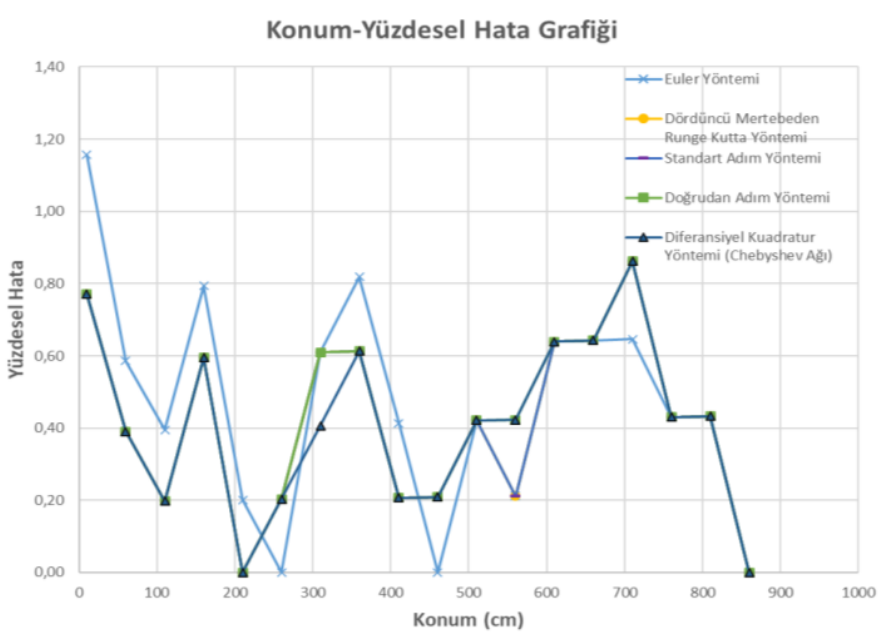

Şekil 5. 2 numaralı deney durumu için sayısal yöntemlerdeki yüzdesel rölatif hataların konuma bağlı değişimi

Tablo 3. 2 numaralı deney durumu için kullanılan sayısal yöntemlerden elde edilen hata değerleri

\begin{tabular}{l|c|c}
\hline Sayısal Yöntem & $\begin{array}{c}\text { Maksimum } \\
\text { Yüzdesel } \\
\text { Rölatif } \\
\text { Hata }\end{array}$ & $\begin{array}{c}\text { Karesel } \\
\text { Ortalama } \\
\text { Hata }\end{array}$ \\
\hline Euler Yöntemi & 1,16 & 0,028 \\
\hline $\begin{array}{l}\text { Dördüncü Mertebeden } \\
\text { Runge Kutta Yöntemi }\end{array}$ & 0,86 & 0,024 \\
\hline Standart Adım Yöntemi & 0,86 & 0,024 \\
\hline $\begin{array}{l}\text { Doğrudan Adım } \\
\text { Yöntemi }\end{array}$ & 0,86 & 0,024 \\
\hline $\begin{array}{l}\text { Diferansiyel Kuadratur } \\
\text { Yöntemi }\end{array}$ & 0,86 & 0,024 \\
\hline
\end{tabular}

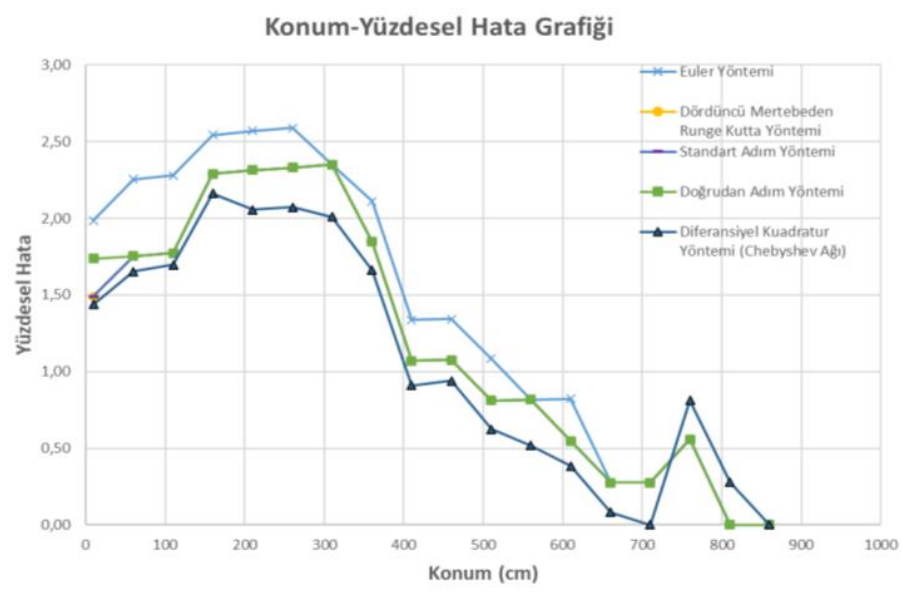

Şekil 6. 3 numaralı deney durumu için sayısal yöntemlerdeki yüzdesel rölatif hataların konuma bă̆lı değişimi

Tablo 4. 3 numaralı deney durumu için kullanılan sayısal yöntemlerden elde edilen hata değerleri

\begin{tabular}{l|c|c}
\hline Sayısal Yöntem & $\begin{array}{c}\text { Maksimum } \\
\text { Yüzdesel } \\
\text { Rölatif } \\
\text { Hata }\end{array}$ & $\begin{array}{c}\text { Karesel } \\
\text { Ortalama } \\
\text { Hata }\end{array}$ \\
\hline Euler Yöntemi & 2,59 & 0,067 \\
\hline $\begin{array}{l}\text { Dördüncü Mertebeden } \\
\text { Runge Kutta Yöntemi }\end{array}$ & 2,35 & 0,058 \\
\hline Standart Adım Yöntemi & 2,35 & 0,058 \\
\hline Doğrudan Adım Yöntemi & 2,35 & 0,058 \\
\hline $\begin{array}{l}\text { Diferansiyel Kuadratur } \\
\text { Yöntemi }\end{array}$ & 2,16 & 0,052 \\
\hline
\end{tabular}

\section{Sonuç}

Yapılan çalışma sonucunda, bağlama arkasındaki su yüzeyi profilinin sayısal hesabı için kullanılan yöntemlerden DKY (Diferansiyel Kuadratur Yöntemi)' nin deneysel verilere daha yakın sonuçlar verdiği gözlenmiştir. Literatürde DKY kullanılarak elde edilen çözümlerin açık ve kapalı sonlu fark şemaları kullanılarak elde edilen çözümlere nazaran analitik çözümlere daha yakın sonuçlar elde edildiği belirtilmektedir. Bu çalışmada da DKY kullanılarak elde edilen sonuçların deneysel sonuçlara daha yakın olduğu görülmüştür. Dolayısıyla, bu tarz bir tasarım probleminde DKY kullanarak hesap yapmanın daha sağlıklı olabileceği söylenebilir.

\section{Teșekkür}

Bu çalışma, Dokuz Eylül Üniversitesi Bilimsel Araştırma Projeleri kapsamında (Proje No: 2020.KB.FEN.027) desteklenmiştir. Dokuz Eylül Üniversitesi Bilimsel Araştırma Projeleri Koordinatörlüğü'ne teşekkür ederiz.

\section{Kaynakça}

Chaudry, M. H. (2008). Open channel flow. New York: Springer Science+Business Media. 
Chow, V. T. (1959). Open channel hydraulics. New York: McGraw-Hill.

Demirel, E. \& Tozluk, H. (2002). Su yüzü profilinin Euler metodu ile sayısal çözümünde gerekli adım sayısının belirlenmesi. Osmangazi Üniversitesi Mühendislik ve Mimarllk Dergisi, 15 (1), 31-40.

Esfandiari, R. S. (2017). Numerical methods for engineers and scientists using MATLAB. Raton, Florida: CRC Press.

Henderson, F. M. (1966). Open channel flow, New York: MacMillan Company.

Kaya, B. (2010). Investigation of gradually varied flows using differential quadrature method. Scientific Research and Essays, 6 (13), 2630-2638.

Manning, R. (1891). On the flow of water in open channels and pipes. Transactions of the Institution of Civil Engineers of Ireland, 10, 161-107.

Marcacuzco, J. A. M. \& Vargas, E. P. (2019). Computation of Gradually Varied Flow by Fourth Order Runge-Kutta Method (SRK). Program adı: 38th IAHR World Congress.

Moglen, G. E. (2015). Fundamentals of open channel flow. Boca Raton, Florida: CRC Press.

Öztürkmen, G. (2008). Açık kanallarda su yüzü profilinin farklı hidrolik koşullar altında belirlenmesi (Yüksek Lisans Tezi). Ulusal Tez Merkezi' nden alınmıştır. (Tez No:255030)

Paine, J. N. (1992). Open channel flow algorithm in NewtonRaphson form. Journal of Irrigation and Drainage Engineering, 118 (2), 306-319.

Qian, H., Zhong L., Bo X. \& Zhenzhen, G. (2011). The research on calculation of water surface profile in channel by Runge Kutta method. 2011 International Symposium on Water Resource and Environmental Protection, 408-412.

Quan, J. R. \& Chang, C. T. (1989a). New insights in solving distributed system equations by the quadrature methods-I. Computational Chemical Engineering, 13, 779-788.

Shu, C. (2000). Differential quadrature and its application in engineering. London: Springer.

Zaghloul N. A. \& Darwish A. Y. (1987). Solution of gradually varied flow problems using the direct step method the IBM Lotus 1-2-3 system, Environmental Software, 2 (4), 199-206.

Basha, A. (2009, Eylül). Experimental verification of gradually varied flow profile computation. Bildiri 6th International Conference on Environmental Hydrology' de sunulmuştur, Kahire.Yayınlanmamıs. 